\title{
Fenotipagem de bactérias isoladas em hemoculturas de pacientes críticos
}

\author{
Phenotyping of bacteria isolated in blood cultures from critical patients
}

\author{
Lara Stefânia Netto de Oliveira Leão ${ }^{1}$, Xisto Sena Passos ${ }^{1}$, Cleomenes Reis ${ }^{1}$, \\ Lêda Maria Almeida Valadão ${ }^{1}$, Maria do Rosário Rodrigues Silva ${ }^{1}$ \\ e Fabiana Cristina Pimenta ${ }^{1}$
}

\begin{abstract}
RESUMO
As infecções da corrente sangǘnea representam uma grave complicação dos pacientes críticos, sendo a detecção de patógenos microbianos em hemoculturas um importante recurso diagnóstico. Esse estudo objetivou isolar e caracterizar bactérias do sangue de pacientes admitidos na unidade clínica de terapia intensiva de um hospital universitário, no período de abril/2003 a abril/2004. As bactérias isoladas foram identificadas por provas bioquímicas/enzimáticas e a detecção do perfil de suscetibilidade aos antimicrobianos pelo método de difusão em disco. Foram avaliadas 304 hemoculturas de 195 pacientes, sendo que 49 (16,1\%) apresentaram desenvolvimento microbiano. A espécie predominante foi Pseudomonas stutzeri (18,2\%). Os cocos Gram-positivos e as enterobactérias apresentaram maior resistência à ampicilina; vancomicina e linezolida foram os agentes mais ativos para cocos Gram-positivos e as carbapenemas para bastonetes Gram-negativos. Devido ao impacto das infecções da corrente sangüinea no contexto hospitalar, estudos adicionais são necessários para subsidiar medidas de prevenção e controle.
\end{abstract}

Palavras-chaves: Bactérias. Sangue. Infecção. Unidade de terapia intensiva.

\begin{abstract}
Bloodstream infections are a serious complication among critical patients. The detection of microbial pathogens in blood cultures is an important diagnostic tool. This study aimed to isolate and characterize bacteria from the blood of patients admitted to the clinical intensive care unit of a teaching hospital, between April 2003 and April 2004. The bacteria isolated were identified by biochemical/enzymatic tests and detection of the antimicrobial susceptibility profile using the disk diffusion method. A total of 304 blood cultures from 195 patients were evaluated. Forty-nine (16.1\%) of the blood cultures presented microbe development. The predominant species was Pseudomonas stutzeri (18.2\%). Gram-positive cocci and enterobacteria showed greater resistance to ampicillin; vancomycin and linezolid were the most active agents for Gram-positive cocci and carbapenems for Gram-negative rods. Because of the impact of bloodstream infection within the hospital context, additional studies are needed in order to give backing for prevention and control measures.
\end{abstract}

Key-words: Bacteria. Blood. Infection. Intensive care unit.

As infecções da corrente sangüínea (ICS) estão entre as mais freqüentes no ambiente hospitalar. Representam uma grave complicação dos pacientes críticos e estão associadas a elevadas taxas de mortalidade e prolongamento do tempo de hospitalização $0^{11}$. Nas últimas décadas, tem sido observado um aumento na incidência das ICS, refletindo, entre outros fatores, a freqüente utilização de recursos invasivos no tratamento e monitoração dos pacientes mais graves ${ }^{2}{ }^{13}$. Esse aumento se refere, particularmente, a utilização do cateter intravenoso, o qual é considerado um dos principais fatores de risco ao desenvolvimento deste tipo de infecção ${ }^{2} 16$.
Do ponto de vista epidemiológico, os cocos Gram-positivos têm emergido como os principais agentes, destacando-se os Staphylococcus aureus, os estafilococos coagulase-negativos (ECN) e os enterococos ${ }^{1114}$. Embora os ECN sejam freqüentemente isolados em hemoculturas, são clinicamente significantes em menos de $15,0 \%$ dos casos $^{16}$. Por fazerem parte da microbiota da pele e apresentarem uma virulência relativamente baixa, são usualmente considerados contaminantes de hemoculturas ${ }^{6}$. Apesar das bacteremias por bastonetes Gram-negativos terem se tornado menos frequientes, a mortalidade associada é maior quando comparada aos cocos Gram-positivos ${ }^{16}$.

\footnotetext{
1. Departamento de Microbiologia, Instituto de Patologia Tropical e Saúde Pública, Universidade Federal de Goiás, Goiânia, GO. Endereço para correspondência: Dr ${ }^{\mathrm{a}}$ Lara Stefânia Netto de Oliveira Leão. Rua 31 ํㅜ 100, Apt $^{0}$ 601, Setor Oeste, $74140-070$ Goiânia, G0. Tel: 5562 3209-6108, Fax: 5562 3521-1839

e-mail: larastefania@yahoo.com.br

Recebido para publicação em: 06/11/2006

Aceito em: 19/09/2007
} 
0 isolamento de bactérias multirresistentes da corrente sanguínea também vem sendo considerado uma tendência dos últimos anos ${ }^{10}$. Vários agentes antimicrobianos têm se tornado menos ativos, reduzindo o número de opções terapêuticas e aumentando o impacto clínico das ICS $^{14}$. Dentre as preocupações relacionadas à resistência antimicrobiana, destacam-se os estafilococos oxacilina resistentes, os enterococos vancomicina resistentes, a produção de beta-lactamases de espectro ampliado (ESBL) por enterobactérias e a resistência das pseudomonas às carbapenemas $^{1014}$.

A detecção de patógenos bacterianos em hemoculturas é considerada um indicador da disseminação de um processo infeccioso e tem sido reconhecida como um importante recurso diagnóstico nos episódios de ICS ${ }^{14}$. Conhecer as bactérias mais freqüentes e o seu perfil de suscetibilidade são essencias ao direcionamento apropriado da terapia antimicrobiana nos pacientes com ICS, contribuindo, assim, para a redução da mortalidade. Desta forma, o presente estudo objetivou identificar e avaliar o perfil de suscetibilidade de bactérias isoladas do sangue de pacientes admitidos na unidade clínica de terapia intensiva de um hospital universitário em Goiânia, Goiás.

\section{MATERIAL E MÉTODOS}

0 estudo foi desenvolvido em uma instituição que presta cuidados terciários, com aproximadamente 12.000 admissões/ ano. A unidade clínica de terapia intensiva possui 8 leitos, sendo um de isolamento e recebe anualmente cerca de 400 pacientes. As coletas dos espécimes foram obtidas após consentimento informado por escrito dos responsáveis. 0 protocolo de investigação foi aprovado pelo Comitê de Ética Regional do Hospital das Clínicas da Universidade Federal de Goiás (UFG) atendendo à resolução 196/96.

No período de abril de 2003 a abril de 2004, foram coletadas 304 amostras de sangue de 195 pacientes. 0 critério de inclusão dos participantes foi a admissão na unidade clínica de terapia intensiva (UTI) do referido hospital durante o período do estudo, idade mínima de 16 anos, independente de gênero e doença de base. As amostras foram coletadas no dia da internação do paciente e a cada sete dias durante a sua permanência na unidade.

Para a realização das hemoculturas, foram coletados $5 \mathrm{~mL}$ de sangue periférico com o uso de agulha e seringa heparinizada, semeados em $15 \mathrm{~mL}$ de caldo infusão de cérebro e coração (Bacto - BD Diagnostic Systems/ USA), homogeneizados e incubados à temperatura de $37^{\circ} \mathrm{C}$ por até 7 dias $^{8}$. Os frascos de hemocultivos foram examinados diariamente para a detecção de sinais de multiplicação microbiana como hemólise, turvação, produção de gás ou formação de depósito ${ }^{8}$.

Evidenciada ou não a presença de desenvolvimento microbiano, todas as hemoculturas com 24 horas, 48 horas e 7 dias de incubação foram repicadas em ágar chocolate $(5 \%$ de sangue de carneiro) e incubadas a $37^{\circ} \mathrm{C} \mathrm{em}$ microaerofilia por 24 a 48 horas, na tentativa de se isolar os possíveis microrganismos presentes na amostra. As bactérias isoladas foram identificadas de acordo com o desenvolvimento das colônias em meios de cultura não-seletivos e seletivos, por provas bioquímicas/ enzimáticas e técnicas automatizadas ${ }^{8}$. Foram utilizadas bactérias controles quando da realização da identificação microbiana (Staphylococcus aureus ATCC 29213, Escherichia coli ATCC 25922 e Pseudomonas aeruginosa ATCC 9027).

A identificação automatizada foi realizada pelo sistema MicroScan $^{\circledR}$ (Dade Behring - West Sacramento, Califórnia, USA), leitor automático autoSCAN $4^{\circledR}$. Para os cocos Gram-positivos, foi empregado o painel Pos Combo 21 e para os bastonetes Gramnegativos o Painel Neg Combo 32.

0 perfil de suscetibilidade das bactérias e a produção de beta-lactamases de espectro ampliado (ESBL) também foram avaliados pelo sistema MicroScan ${ }^{\circledR}$. A suscetibilidade dos isolados foi determinada pela concentração inibitória mínima (CIM) e os resultados reportados como sensível, resistência intermediária ou resistente com base na interpretação dos breakpoints, segundo as recomendações da National Committees of Clinical and Laboratory Satandards (NCCLS 2003), recentemente denominada de Clinical and Laboratory Standards Institute (CLSI) ${ }^{8}$.

\section{RESULTADOS}

Os 195 pacientes avaliados tiveram número de coletas variável, em virtude do período de permanência na unidade (Tabela 1). Da maioria dos pacientes foi coletada apenas uma amostra de sangue, correspondente ao dia da internação.

Tabela 1 - Número de bemoculturas coletadas de pacientes internados na unidade clínica de terapia intensiva de um bospital universitário em Goiânia-Goiás, abril de 2003 a abril de 2004.

\begin{tabular}{cc}
\hline Hemoculturas $\left(\mathrm{n}^{0}\right)$ & Pacientes $\left(\mathrm{n}^{\circ}\right)$ \\
\hline 1 & 136 \\
2 & 36 \\
3 & 11 \\
4 & 7 \\
5 & 2 \\
7 & 1 \\
8 & 1 \\
10 & 1 \\
\hline
\end{tabular}

Dentre as 304 hemoculturas coletadas, $49(16,1 \%)$ apresentaram desenvolvimento microbiano. Foram isolados 51 microrganismos, sendo 7 (13,7\%) leveduras e $44(86,3 \%)$ bactérias. Em 2 hemoculturas foram isolados, simultaneamente, 2 tipos diferentes de microrganismos. Os cocos Gram-positivos corresponderam a 47,7\% (21) dos isolados, enquanto os bastonetes Gram-negativos representaram 50\%, sendo 27,3\% (12) caracterizados como não-fermentadores e 22,7\% (10) enterobactérias. Foi identificado um (2,3\%) bacilo Gram-positivo corineforme.

Na Tabela 2, está apresentada a identificação das bactérias isoladas nas hemoculturas dos pacientes. A espécie predominante foi a Pseudomonas stutzeri (18,2\%), seguida pela 
Klebsiella pneumoniae (13,6\%) e Staphylococcus aureus (13,6\%), Staphylococcus sp (11,3\%), Enterococcus faecalis (6,8\%), Proteus mirabilis (6,8\%), Staphylococcus epidermidis (6,8\%) e Acinetobacter baumannii (4,5\%). Burkbolderia cepacia, Corynebacterium sp, Enterobacter cloacae, Micrococcus sp, Pseudomonas aeruginosa, Staphylococcus bominis, Staphylococcus simulans e Staphylococcus warneri corresponderam, cada um, a 2,3\% dos isolados.

Tabela 2 - Identificação de 44 bactérias isoladas em bemoculturas de pacientes internados na unidade clínica de terapia intensiva de um hospital universitário em Goiânia-Goiás, abril de 2003 a abril de 2004.

\begin{tabular}{|c|c|c|}
\hline Bactérias & Número & Porcentagem \\
\hline \multicolumn{3}{|l|}{ Cocos Gram-positivos } \\
\hline Staphylococcus aureus & 6 & 13,6 \\
\hline Staphylococcus sp & 5 & 11,3 \\
\hline Staphylococcus epidermidis & 3 & 6,8 \\
\hline Staphylococcus hominis & 1 & 2,3 \\
\hline Staphylococcus simulans & 1 & 2,3 \\
\hline Staphylococcus warneri & 1 & 2,3 \\
\hline Enterococcus faecalis & 3 & 6,8 \\
\hline Micrococcus sp & 1 & 2,3 \\
\hline \multicolumn{3}{|c|}{ Bastonetes Gram-negativos não fermentadores } \\
\hline Pseudomonas stutzeri & 8 & 18,2 \\
\hline Pseudomonas aeruginosa & 1 & 2,3 \\
\hline Acinetobacter baumannii & 2 & 4,5 \\
\hline Burkbolderia cepacia & 1 & 2,3 \\
\hline \multicolumn{3}{|c|}{ Bastonetes Gram-negativos fermentadores } \\
\hline Klebsiella pneumoniae & 6 & 13,6 \\
\hline Proteus mirabilis & 3 & 6,8 \\
\hline Enterobacter cloacae & 1 & 2,3 \\
\hline \multicolumn{3}{|l|}{ Bacilo Gram-positivo corineforme } \\
\hline Corynebacterium sp & 1 & 2,3 \\
\hline
\end{tabular}

Em relação ao perfil de suscetibilidade antimicrobiana dos cocos Gram-positivos, todos os isolados caracterizados como Staphylococcus aureus e 83,3\% dos estafilococos coagulase negativos (ECN) foram resistentes à ampicilina. Observou-se uma elevada taxa de resistência à oxacilina $(66,7 \%)$ entre estes isolados. Todos os cocos Gram-positivos foram sensíveis à linezolida e à vancomicina, e $68,7 \%$ ao trimetoprim-sulfametoxazol.

Entre as enterobactérias, a maior taxa de resistência observada foi para ampicilina (100\%), seguida pelo trimetoprim-sulfametoxazol (70\%) e piperacilina (60\%). Todos os isolados foram sensíveis as carbapenemas e três Klebsiella pneumoniae (50\%) foram produtoras de beta-lactamases de espectro ampliado (ESBL).

A taxa de sensibilidade dos bastonetes Gram-negativos não fermentadores às carbapenemas também foi elevada (91,6\% dos isolados). As pseudomonas apresentaram taxa de resistência ao aztreonam de $77,8 \%$ e à amicacina de 55,5\%.

\section{DISCUSSÃO}

Durante o período de 12 meses, foram analisadas 304 hemoculturas de 195 pacientes admitidos na unidade clínica de terapia intensiva de um hospital escola de Goiânia, Goiás. A taxa de hemoculturas positivas foi de 16,1\%. Taxas semelhantes foram relatadas em outros estudos ${ }^{41617}$. Uma emergência de cocos Gram-positivos como os agentes mais prevalentes nos episódios de ICS têm sido observada, mas nesta investigação a frequiência de isolamento dos cocos Gram-positivos (21 isolados) e dos bastonetes Gram-negativos (22 isolados) foi similar.

A bactéria mais prevalente nas hemoculturas analisadas foi a Pseudomonas stutzeri (18,2\%). Apesar de ser considerada saprófita, e raramente causar infecção, esta bactéria está relacionada a surtos de bacteremia, geralmente, por soluções endovenosas ou equipamentos utilizados em processos de diálise $\mathrm{e}^{3}$. Os sítios de infecção por Pseudomonas stutzeri mais comuns são: trato respiratório, trato urinário e corrente sanguiínea. Osteomielite, artrite séptica e meningites causadas por bacteremia disseminada também têm sido descritas ${ }^{37}$.

Neste estudo, os sete $(17,1 \%)$ pacientes que apresentaram hemocultura positiva para Pseudomonas stutzeri apresentavam doença de base crônica como insuficiência respiratória ou renal, fizeram uso de mais de um antimicrobiano durante o tempo de internação na UTI e foram submetidos ao mínimo de 2 procedimentos invasivos tais como: sonda nasoentérica e cateter intravascular. Destes sete pacientes, dois foram a óbito.

Entre os cocos Gram-positivos a espécie mais comum foi 0 Staphylococcus aureus (6 isolados), sendo que destes 66,7\% foram resistentes à oxacilina. Nesta mesma instituição, foram descritas taxas de resistência de $61 \%{ }^{4}$. Dados semelhantes foram observados em outros hospitais brasileiros, onde os Staphylococcus aureus resistente à meticilina (MRSA) representaram de 26,6\% a $71 \%$ dos isolados ${ }^{19}$.

o Staphylococcus epidermidis foi a espécie mais freqüente entre os estafilococos coagulase negativos (ECN). Uma elevada taxa de resistência à oxacilina também foram observadas entre os $\operatorname{ECN}(66,7 \%)$. Os enterococos isolados não apresentaram características relevantes. Corresponderam a 6,8\% (3 isolados) do total de bactérias isoladas, todos foram sensíveis à oxacilina, à vancomicina e ao trimetoprim-sulfametoxazol, mas resistentes ao synercid. A ampicilina foi o antibiótico menos ativo para os cocos Gram-positivos e vancomicina e linezolida os agentes mais ativos.

Entre os bastonetes Gram-negativos fermentadores, Klebsiella pneumoniae foi a espécie predominante (60\%), seguida do Proteus mirabilis (30\%). Estes isolados estão entre os Gramnegativos mais freqüentemente reportados em hemoculturas ${ }^{915}$. Três Klebsiella pneumoniae (50\%) produziram beta-lactamase de espectro ampliado (ESBL).

A ampicilina também foi o antibiótico menos ativo para as enterobactérias, enquanto as carbapenemas (imipenem e meropenem) foram os agentes antimicrobianos mais ativos, seguida da gentamicina e quinolonas (ciprofloxacina e levofloxacina). Este perfil de sensibilidade dos BGN fermentadores, particularmente das Klebsiella pneumoniae, também foi relatado por outros estudos ${ }^{514}$.

As pseudomonas apresentaram resistência à maioria dos agentes antimicrobianos. A maior taxa de resistência foi observada 
ao aztreonam $(77,8 \%)$ e a amicacina, um pseudomonicida por excelência, foi ativa apenas para $44,4 \%$ dos isolados. Imipenem e meropenem foram os agentes mais ativos, com 100\% e 88,9\% de atividade, respectivamente.

A detecção de patógenos bacterianos em culturas de sangue e a avaliação de seu perfil de suscetibilidade fornecem dados importantes para a racionalização da terapia antimicrobiana e redução das taxas de mortalidade. Porém, devido ao impacto das ICS no contexto hospitalar, estudos adicionais são necessários para a elaboração e implementação de medidas mais efetivas de prevenção e controle das infecções nosocomiais, diminuindo custos hospitalares e qualificando os serviços oferecidos pelas equipes de saúde.

\section{REFERÊNCIAS}

1. Costa JM, Ramos IB, Carvalho DJ, Dias Jr R. Análise da sensibilidade de Staphylococcus aureus hospitalar aos antimicrobianos no período de 1988 a 1993. In: Resumo do IV Congresso Brasileiro de Controle de Infecção Hospitalar, Recife p. 83, 1994.

2. Diekema DJ, Beekmann SE, Chapin KC, Morel KA, Munson E, Doern GV. Epidemiology and outcome of nosocomial and community-onset bloodstream infection. Journal of Clinical Microbiology 41: 3655-3660, 2003.

3. Fernandes AT, Furtado JJD, Porfírio FMV, Cavalcante NJF. Infecção Hospitalar da Corrente Sangüínea. In: Fernandes AT, Fernandes MOV, Ribeiro Filho N (eds) Infecção Hospitalar e suas Interfaces na Área de Saúde, $1^{2}$ edição, Editora Atheneu, São Paulo, p. 508-606, 2000.

4. Guilarde A0. Bacteremias em hospital universitário: incidência, perfil de suscetibilidade antimicrobiana e fatores prognósticos para o óbito. Dissertação de Mestrado, Universidade Federal de Goiás, Goiânia, GO, 2003.

5. Karlowsky JA, Jones ME, Draghi DC, Thornsberry C, Sahm DF, Volturo GA. Prevalence and antimicrobial susceptibilities of bacteria isolated from blood cultures of hospitalized patients in the United States in 2002. Annals of Clinical Microbiology Antimicrobial 3: 1-8, 2004.

6. Khatib R, Riederer KM, Clark JC, Khatib S, Briski LE, Wilson FM. Coagulase-negative staphylococci in multiple blood cultures: strain relatedness and determinants of same strain bacteremia. Journal of Clinical Microbiology 33: 816-820, 1995.
7. Koneman EW, Allen SD, Janda WM, Schreckenberger PC, Winn WCJ. Diagnóstico Microbiológico-Texto e Atlas Colorido. Editora Medsi, Rio de Janeiro, 2001.

8. Koneman EW, Allen SD, Janda WM, Schreckenberger PC, Winn WCJ. Bacilos Gram-Negativos Não-Fermentadores. In: Koneman EW, Allen SD, Janda WM, Schreckenberger PC, Winn WCJ (eds) Diagnóstico Microbiológico-Texto e Atlas Colorido, $5^{2}$ edição, Editora Medsi, Rio de Janeiro, p. 264-329, 2001.

9. Levy CE, Montelli AC, Furtado JS, Pereira AA, Mamizuka EM, Silva MLR, Francisco W. Resistência a drogas em cepas bacterianas de pacientes de serviços hospitalares: laboratório de referência do sistema COBA. Revista de Microbiologia 22: 21-27, 1991 .

10. Linden PK. Clinical Implications of Nosocomial Gram-Positive Bacteremia and Superimposed Antimicrobial Resistance. The Americam Journal of the Medical Sciences 104: 24-33, 1998.

11. Munson EL, Diekema DJ, Beekmann SE, Chapin KC, Doern GV. Detection and treatment of bloodstream infection: laboratory reporting and antimicrobial management. Journal of Clinical Microbiology 41: 495-497, 2003.

12. National Committee for Clinical Laboratory Standards (NCCLS). Performance standards for antimicrobial susceptibility testing. Documents M100-S13. Wayne, PA, USA, 2003.

13. National Nosocomial Infections Surveillance System (NNIS). Nosocomial infection rates for interhospital comparison: limitations and possible solutions. Infection Control and Hospital Epidemiology 12: 609-621, 1991.

14. Pfaller MA, Jones RN, Doern GV, Kugler K. Bacterial pathogens isolated from patients with bloodstream infection: frequencies of occurrence and antimicrobial susceptibility patterns from the SENTRY antimicrobial surveillance program (United States and Canada, 1997). Antimicrobial Agents and Chemotherapy 42: 1762-1770, 1998

15. Ronveaux O, Jans B, Suetens C, Carsauw H. Epidemiology of nosocomial bloodstream infections in Belgium, 1992-1996. European Journal of Microbiology and Infectious Disease 17: 695-700, 1998.

16. Weinstein MP, Towns ML, Quartey SM, Mirrett S, Reimer LG, Parmigiani C, Reller LB. The clinical significance of positive blood cultures in the 1990's: a prospective comprehensive evaluation of the microbiology, epidemiology and outcome of bacteremia and fungemia in adults. Clinical Infectious Diseases 21: 584-602, 1997.

17. Yinnon AM, Schlesinger Y, Gabbay D, Rudensky B. Analysis of 5 Years of Bacteraemias: Importance of Stratification of Microbial Susceptibilities by Source of Patients. ]ournal of Infection 35: 17-23, 1997. 